\title{
A simulation-based performance investigation of downstream operations in the Indian Surimi Supply Chain using environmental value stream mapping
}

\author{
Farook Abdullah Sultan ${ }^{\mathrm{a}, *}$, Srikanta Routroy ${ }^{\mathrm{a}}$, Maitri Thakur ${ }^{\mathrm{b}}$ \\ a Department of Mechanical Engineering, Birla Institute of Technology, Pilani Campus, Rajasthan, 333031, India \\ b SINTEF Ocean, Brattørkaia 17C, Trondheim, Norway
}

\section{A R T I C L E I N F O}

\section{Article history:}

Received 8 May 2020

Received in revised form

19 November 2020

Accepted 1 December 2020

Available online 4 December 2020

Handling editor: Cecilia Maria Villas Bôas de Almeida

\section{Keywords:}

Surimi supply chain

Value stream mapping

Sustainability

Partial vertical integration

Complete vertical integration

\begin{abstract}
A B S T R A C T
The consumption of surimi made from fish has begun to see a continuous rise in demand owing to vast availability, low pricing and copious protein content. Despite visible improvements in processing and distribution trends of Indian surimi, the downstream operations of the surimi supply chain in specific lacks performance due to prolonged delays, extended waiting times and diminishing fish quality. The rising fossil fuel prices, associated emissions and increased focus on energy utilization for organizational sustainability have made this inefficiency a supply chain concern. This has indeed created a room to adjust the existing supply chain design. This work integrates the principles of lean and carries out an environmental analysis observing the utilization of water, energy and raw materials along the supply chain followed by the identification and elimination of wastes. This article aims in eliciting sustainability in downstream operations in the Indian surimi supply chain by identifying and optimizing supply chain operations using Value Stream Mapping (VSM). VSM is used as a tracking tool to capture the existing downstream operations of the surimi supply chain and propose different alternatives. Performance analysis was carried out along sustainability for different supply chain integration scenarios namely No vertical integration, Partial vertical integration and Complete vertical integration using value stream mapping and discrete event simulation model developed. It was observed that the supply chain with complete vertical integration would provide better performance in comparison to other supply chain design alternatives considered. The supply chain with complete vertical integration will reduce $74.52 \%$ of lead time, $79.68 \%$ of emissions and $81.66 \%$ of energy consumption compared to the current state. Therefore, creating a surimi supply chain with cleaner downstream operations that will lead to sustainability enhancement.
\end{abstract}

() 2020 Elsevier Ltd. All rights reserved.

\section{Introduction}

Fishing has been a source of livelihood for 14 million people in India, constituting $6.3 \%$ of the global fish production (NFDB, 2016) and is among the top five global fish capturing nations. Fetching a value of $\$ 7.08$ billion during the financial year 2017-18 (Nambudri, 2018), global exports are expected to double in the years to come. Processed seafood has gained a significant consumer market worldwide, amongst which 'surimi' has been of higher demand constituting a value share of $2.5 \%$ of the total processed seafood

\footnotetext{
* Corresponding author.

E-mail addresses: abdullahsultan1991@gmail.com (F.A. Sultan), srikantaroutroy@gmail.com (S. Routroy), Maitri.Thakur@sintef.no (M. Thakur).
}

export earnings (Dasgupta et al., 2019). Being an intermediate material for producing various seafood products (Park, 2005), 'surimi' is made of low-cost pelagic fishes. Originated in Japan in the year $1100 \mathrm{AD}$ (Gopakumar, 2002) and termed as 'Kambako' in Asia, surimi is a main ingredient in the making of processed seafood products like fish balls, crab sticks, etc. Utilizing species like pink perch, ribbon fish, lizard fish, bronze croaker, reef cod and crocker fish, the entire surimi produced in India is exported worldwide and is in increasing trends. Quality embracement being the primary objective for market sustenance requires high costs; the constraint to cut down, which takes a critical factor in any supply chain. This, as a result, lays a negative impact on various aspects such as fish quality, cost, profitability and quality of the product produced. Fish quality plays a vital role in surimi and Value-Added Products (VAPs) 
such as fish meal, fish oil, fish paste, etc. With mounting quality essentials such as EU directive 178/2002, rising production requirements and a check over the continuously depleting fossil fuels, a critical analysis of the various losses and allied environmental aspects of the Indian Surimi Supply Chain (SSC) is required. The demanding requirements of global fisheries have enforced several researchers to study the energy expenses in fishing and postharvest operations in recent years (Parker and Tyedmers, 2015). Energy consumption being the threshold in the current fishery sector, has a significant impact on the productivity of the fishers in terms of catch volume. Increasing fishing pressures (Ravi et al., 2014) has demanded Indian fishers to shift from the conventional, less environmentally friendly, efficient boats to motorized non-eco-friendly efficient machines in recent years. The rising energy prices, growing climatic concerns and an accompanying increase in the level of emissions strictly necessitate the analysis of the relative energy performance (Parker and Tyedmers, 2015). However, the qualitative usage of accessible energy forms is obligatory for sustainable development (Paul and Bhattacharya, 2004). Demanding a fuel of 1220 million liters and an estimated Greenhouse Gas emission of $1.13 \mathrm{t}$ per ton of fish caught (Boopendranath, 2006), the fishing industry is a marked consumer of fossil fuels. Although the role of the fishing sector in an amplified energy depletion scenario is meager by accounting $1.2 \%$ of global oil consumption (Tyedmers et al., 2005), the ecological harms and reduced productivity in terms of nutritional energy vs. energy utilized (Tyedmers, 2004) necessitate the understanding of all the activities involved in the SSC. Added obligation further rises with the low utilization of fish/surimi by-products generated with considerable market demand after processing. Surimi processing operation produces head, gut and skin termed as Rest Raw Material (RRM) that is generally discarded as waste in some cases or processed by specific secondary industries to VAPs (detailed in Section 4.3). This hence demands a sustainably performing Indian SSC with reduced resource wastage considering the socio-environmental impacts of the organization (Garza-Reyes et al., 2016).

The supply chain configuration in India involves the processing and downstream operations of surimi and VAPs operating efficiently with well-defined roles and stakeholder responsibility. However, the downstream activities of these supply chains, starting from the fishing operation to the receiving of raw material at the processing stage, lacks supply chain performance in terms of longer lead times and higher energy consumption. The fragmented ownership, fishing area identification, fishing boat \& its capacity, boat unloading practice, real-time information sharing, manual inspections, manual touchpoints, temperature measurement system, non-standard cold chain, high raw material (i.e. fish and RRM) supply variability and location of the operations create barriers from the Indian SSC becoming an efficient supply chain (Routroy et al., 2019). All these factors in total necessitate understanding the non-value adding activities involved in the process of surimi production. Management of these issues is conceivable from further investments, whereas the amount of expenditure goes unquoted. Exploring better solutions to reduce costs is evident (Stadnicka and Litwin, 2019) and hence needs to be explored.

Introducing the concept of lean in the food supply chain despite its low numbers in literature (Chen et al., 2020), is conditional to the deficiency to comprehend the nature of waste and elimination techniques to be adopted (Folinas et al., 2013). The current study utilizes Value Stream Mapping (VSM) as a lean tool to identify the various wastes generated in the downstream operations of the supply chain. Outcomes obtained are further analyzed considering the effect of different levels of Supply Chain Integration (SCI) (i.e. No Vertical Integration (NVI), Partial Vertical Integration (PVI) \& Complete Vertical Integration (CVI)) on environmental sustainability and its effect on the operational performance of the supply chain. By adopting CVI with reduced emissions and energy consumption, the authors express that the current work will lead to a cleaner production in the Indian SSC with reduction of various wastes such as Lean wastes (i.e. Waiting, Transportation, Processing, Inventory and Movement \& Quality) and Green wastes (i.e. Energy, Water, Materials, Waste, Transport \& Emissions). The research article also proposes to develop a simulation model affirming environmental consequences considering the downstream operations of the SSC in India. This work aims to contribute to the academic community, production managers and policymakers in exploring possibilities of implementable improvements in the Indian stance, followed by reaping benefits of green innovations in gaining a competitive edge over their competitors (Carvalho et al., 2017). The contribution of this work is summarised as follows:

(i) To construct Environmental VSM for downstream operations of Indian SSC.

(ii) Recommend improvements for a sustainable SSC.

(iii) Generate a Discrete Event Simulation (DES) model.

(iv) To perform economic analysis for various $\mathrm{SCI}$ alternatives.

The research is structured as stated: Section 2 provides literature related to lean tools implementation and potential use of VSM in the fishing sector, Section 3 presents the methodology adopted in accomplishing the research, Section 4 discusses scenario investigation using VSM and Section 5 highlights the future state environmental VSM constructed. Section 6 converses the results and discussions, whereas conclusions and future scope of the current work are specified in Section 7.

\section{Theoretical background}

\subsection{The lean concept}

The paradigm of lean holds appropriate for the food supply chain owing to the uncertainty existing at the customer end empowering switching sources, shorter shelf life demanding flexible production and delivery, increased quality requirements, cost and availability (Folinas et al., 2013). Introduced to upkeep organizational efficiency (Barth and Melin, 2018), the concept of lean hosted for the production sector has extended its applicability into domains such as administration (Belayutham et al., 2016); public administration (Mustosmäki et al., 2020); healthcare (Henrique et al., 2020) and service sector (Piercy and Rich, 2009). In precise, the principles of lean emphasis on pull production, waste elimination, streamlining of processes, zero defects, continuous improvements and quality at the source that have been implemented across diverse disciplines and proven commendable (Kumar et al., 2018). The concept of lean objects itself in the identification and elimination of wastes by the usage of appropriate lean tools and techniques (Shah and Word, 2003). Apart from waste reduction (i.e. non-value-adding activities involving excess time, labour, equipment, space and inventory), lean techniques post-implementation have shown to assist firms in gaining monetary benefits with improvements in quality, operating costs and cycle time (Cudney and Elrod, 2011). The lean tools and techniques commonly found to be used in literature are one-piece flow, visual control, Kaizen, cellular manufacturing, inventory management, Poka-yoke, standardized work, just in time, set up reduction, Value Stream Mapping (VSM), Total Productive Maintenance, workplace organization and scrap reduction to reduce manufacturing waste (Russell and Taylor, 2008). Lean application in a fragmented supply chain (SSC in our case) requires mapping for identifying and eliminating wastes from 
the system (Pavnaskar et al., 2003). VSM is adopted as a primary tool for implementing improvements by identifying operational wastes and oversees the material and information flow used to design the system (Rother and Shook, 2003). Efficacious applications of VSM in food supply chains have been reported in the literature with VSM used in enhancing operational performance of food processing industries in Ghana (Pokuaa-Duah and Nadarajah, 2020); tomato supply chain in Greece (Anastasiadis et al., 2020); dairy industry (Melin and Barth, 2020), Agri-food supply chain (Kumar and Kushwaha, 2015) etc.. Mapping is generally proceeded by the process of waste identification using Kaizens. Focusing on waste reductions and operation improvements (Kumar et al., 2018), Kaizens or continuous improvement have been accepted worldwide with its practical competency of combining waste elimination tools and techniques effectively (Melcher et al., 1990). Represented by Kaizen blitz denoting identified wastes/improvements required (Engelund et al., 2009), the fusion of lean tools and Kaizens is a considerably reported amalgamation technique (Zahoor et al., 2019; Kumar et al., 2018) that has been adopted in this article.

\subsection{Environmental value stream mapping}

Addressing the perception of sustainability, research using lean regulating the operation environment and its integration with green principles has been a topic of progress recently (Garza-Reyes, 2018; Chiarini, 2014). King and Lenox (2001) analyzed the effect of lean on the environment and concluded that lean principles removed the barriers to pollution that had been expensive traditionally. Larson and Greenwood (2004) extended the claim stating that the decline in material usage and energy consumption lead to eco-friendly scenarios. Generally termed as "green," integration into lean chiefly emphasizes on the environmental effect instigated by the production activity (Baumer-Cardoso et al., 2020) stressing on waste elimination such as redundant and mismanaged use of resources like water, power and wastes like environmental effluence, litter, greenhouse effects and environmental eutrophication (Cherrafi et al., 2016). With the terms lean and green being often substitutive (Garza-Reyes, 2015; Faulkner and Badurdeen, 2014), authors have claimed it to be in synergy (Carvalho et al., 2017). Hence, to reflect the various issues mentioned above, threefold use of VSM capturing critical Value-Added (VA), Non-Value Added (NVA) activities, resource utilization and associated energy usage quantifying emissions released at each operation is required. Analogous works were done by Wills (2009) and Kurdve et al. (2011), integrating the environmental characteristic into the value stream and termed it as a green/environmental value stream map. Practices have also evolved using sustainable VSM tools that integrate both environment and sustainability metrics. The tool was applied and checked for aptness by Brown et al. (2014) in visualizing the sustainability metrics for three cases considered in their study.

\subsection{Supply chain integration}

A well-documented influence that has produced performance enhancement (operational and environmental performance) in supply chain operations is via integration of supply chains (Song et al., 2017). Functional via the extension of management focus covering both in-house and external stakeholders (Geary et al., 2002), supply chain integration reduces the level of risk persisting in supply chains. This is done by efficiently transferring information and coordinated operations (Liu and Lee, 2018). Increased SCI leads to improved environmental sustainability (Wiengarton and Longoni, 2015). The combination of sustainable/green supply chains with SCI has led to the rise of a novel branch of Green supply integration (Song et al., 2017). This branch converges on the idea of strategic supply chain partnerships between stakeholders handling both intra and inter-organizational operations (Wong et al., 2015) thereby greening the supply chain. The purpose served in this article however is to focus on extending the green efforts/practices across the supply chain followed by emphasizing the importance of supply chain integration (Wong et al., 2015) and quantifying its effect on the environment. The concept of integration in supply chains is still naive (Chaudhuri et al., 2018), and hence needs further investigation. This work furthermore entails a DES approach antecedent to the conventional VSM, elucidating the impacts of integration. VSM used as a static tool comprises a series of inadequacies (Gurumurthy and Kodali, 2011) which get overcome from simulations. Apart from the literatures mentioned above, a detailed list of literature summarised is represented in the E-component.

\subsection{Research gap}

An extensive literature survey established the availability of sufficient work on green supply chain integration (Han and Huo, 2020; Wu, 2013). However, such applications in a seafood supply chain were absent, with no study found mainly in India. Similar outcomes were also observed with VSM despite its focus on a wide range of applications and a visible deficiency in the seafood supply chain. This work tries to fill this gap in the literature by incorporating the concepts of lean, environmental sustainability, SCI and DES to gain an insight into the actual and the improved scenario. The use of lean principles on eco-sustainability in the SSC, according to the author, is an unventured route; however, a plethora of work was found to be available on sustainable seafood industries (Gómez-Sanabria et al., 2020; Mannacharaju et al., 2020). The domain of research adopted in this article being a comparatively innovative application of the sustainable lean philosophy requires gaining a deep understanding of the Indian fishing process. The concept of SCI has been introduced as it leads to better supply chain performance overcoming disruptions providing an economical and competitive advantage (Revilla and Saenz, 2017). This paper impacts the development of a structured Indian SSC that allows us to explore and analyze improvements focusing on quality and environmental impression in the SSC. Conclusions derived from simulations provide a quantitative deduction of the preferred performance indicators. Contemplation of literature surveyed, conclude the subsequent gaps which researchers have failed to address:

- No evidence of studies on operational and environmental wastes in the Indian SSC

- Kaizen adoption based on stakeholder acceptability in the Indian SSC

- Integrating DES to highlight resource utilization in the seafood supply chain assisting in better decision making

- Propose supply chain moderations and project post-enactment revenues in each case of integration.

\section{Proposed Research Methodology}

A diagrammatic representation of the adopted methodology is represented in Fig. 1. The entire procedure is classified into four steps (i.e., gaining overview, current state map construction, future state map construction and analysis followed by the conclusion). Dialogues with stakeholders, both internal and external to the organization, concluded the deficiency in potential exploitation of surimi and associated RRM generated due to the unorganized and fragmented nature of the supply chain (Refer Fig. 2). Containing 


\section{STEPS}

Refer:- Section I, II Supplementary sheet

Refer:- Section IV

Refer:- Section VIVIII

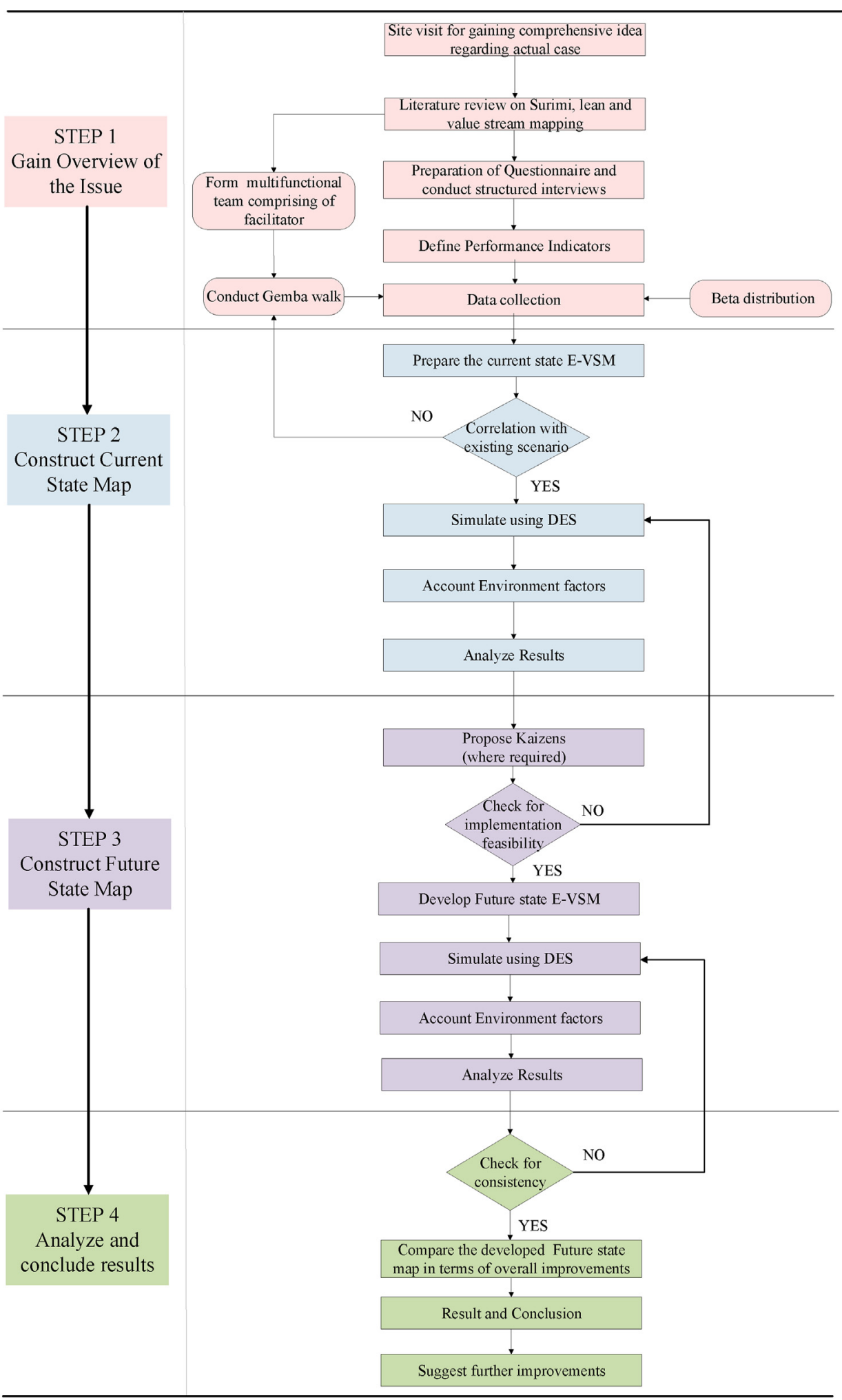

Fig. 1. Research methodology.

multiple marginal players and downstream operations leads explicitly to reduced supply chain profitability, with quality being a concern only at the final processing stage. The existing processes deficit systematics and proper logistics, followed by an ineffectually managed cold chain. Construction of the current state map is followed by the identification of wastes existing in the supply chain. Environmental scheming is carried out mutually using shorthand calculations and from results obtained via simulation. This study 


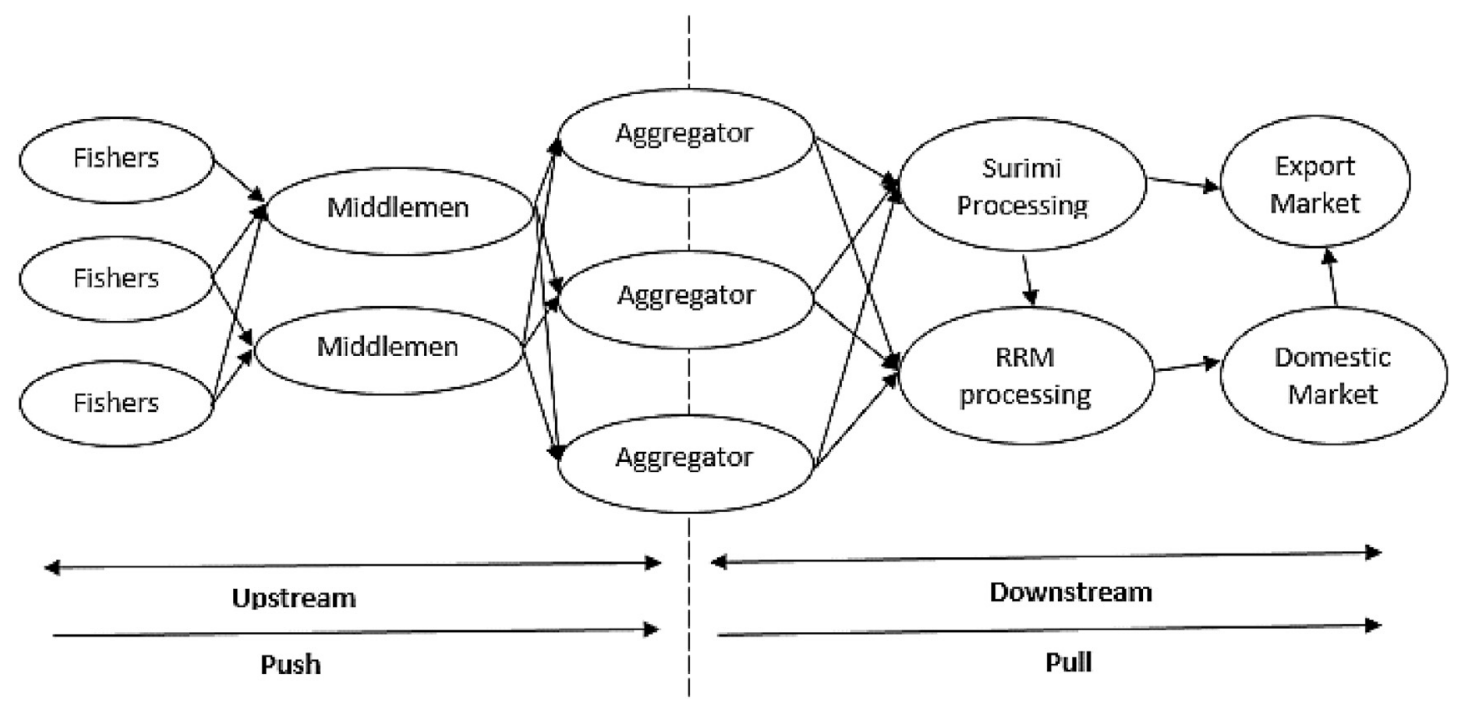

Fig. 2. Surimi supply chain in India (Modified after Routroy et al., 2019).

requires simulation support due to its ability to categorize risks instigated via interactions between simultaneously operating operations (Thiede et al., 2016).

\section{Scenario investigation using VSM}

The adopted methodology is validated by gaining an in-depth insight into the surimi/RRM production process in India (Refer Fig. 3). A processing plant in Mumbai and Mangalore were selected as case organizations. Particulars of the companies have not been shared to maintain confidentiality. Sited in Mumbai, the surimi producing company $(\mathrm{ABC})$ has an in-house production capacity of $24 \mathrm{MT} /$ day and operates production from August to June. Fish is supplied from 15 sources within the Mumbai coastal area, with supply primarily depending upon catch species and surimi demand. RRM generated is procured by firms for further utilization located at a distance of $900 \mathrm{~km}$. The research team spent 2 weeks at the fishing dock, processing side of surimi, RRM, to gain a deep impression of the complete process. Necessary information was acquired through semi-structured interviews with the processing plants and fishers supplying fish through an aggregator to surimi industries.

Commencement of surimi/RRM production begins with fishing vessels moving into the ocean for 7-10 days with ten tons of ice with a boat capacity of 25 MT. Each fishing trip targets available fish species with every haul followed by the layering of crushed ice over the catch in storage containers preventing quality deterioration. This process is recurrent until the storage is complete or till sufficient fuel exists for returning to the dock. On arrival, the chilled fish is de-iced, unloaded manually and transported to the surimi and RRM processing plants via de-heading units. The organization dispatches shipments of surimi based on orders received and adopts a make to stock type production using large refrigerated buffers/storage units.

\subsection{Structuring the current state environmental VSM}

Analyzing the existing state of the SSC revealed the fishing phase to be the bottleneck operation obliging the appropriate supply of raw material to the processor. With deterioration in fish quality being rapid (Thorpe and Bennet, 2004) and preventive measures like iced storage in the fishing boat and onshore cold storages used, additional steps are needed to preserve and monitor temperature abuse, to reduce wastage and ensure food safety. As fishing is a time-sensitive activity, the time consumption data is highly uncertain if variability is not signified. This issue is overcome by applying Beta distribution over the measured time (Refer Ecomponent). The time spent for the fishing operation is maximum with 9.33 days and further processing occurs downstream. Preliminary studies conclude that despite the number of VA activities contributing $40.20 \%$ and NVA contributing $59.8 \%$ in total, the timeshare contribution for VA is a mere $39.08 \%$ compared to the NVA. The environmental VSM developed signifies the VA and NVA parameters sideways to energy (liters), raw material usage and power consumed $(\mathrm{kWh})$ in the entire process with emissions generated from logistics. Although different types of boats are used for fishing, a standard boat size was considered for the study and its average values of fuel and power consumption are detailed in Table 1. One-year historical data was retained for scheming the maps and are signified using standard symbols represented in Fig. 4, categorizing and measuring the seven environmental wastes. The environmental wastes (i.e., energy, water, materials, garbage/ waste, transport, emissions and bio-diversity) taken note in this work are adapted from Faulkner and Badurdeen (2014). Biodiversity has not been signified as an industrial waste owing to its incoherence with the scope of the study. Four value stream maps are constructed to map the current state of the SSC (Refer Appendix; Fig A1- Fig A4).

Processing time $\left(T_{p}\right)$, Lead Time $\left(L_{T}\right)$, Process cycle efficiency(PCE), Value Added Time(VAT), Non-Value Added Time(NVAT) are used as performance evaluators for the Supply chain. This selection was done owing to its wide usage in literature (Abideen and Mohamad, 2020; Stadnicka and Ratnayake, 2015) and are signified in detail in the E-component. Emission calculations of the fishing vessels are done as per the IPCC values mentioned by Jun et al. (2002) and logistic emission values specified by Salama et al. (2015) (Refer E-component). The fishing boat emissions are highlighted as carbon dioxide equivalent (comprising carbon dioxide, methane, oxides of nitrogen and NMVOC (Non-Methane Non-Volatile Organic Compounds, i.e., benzene, ethanol, formaldehyde etc.) and calculated using equation (1).

Emission $=$ Fuel consumed (liter) $*$ Emission Factor $(\mathrm{g} / \mathrm{kg}$ fuel $)$

(Source; Jun et al. (2002)) 


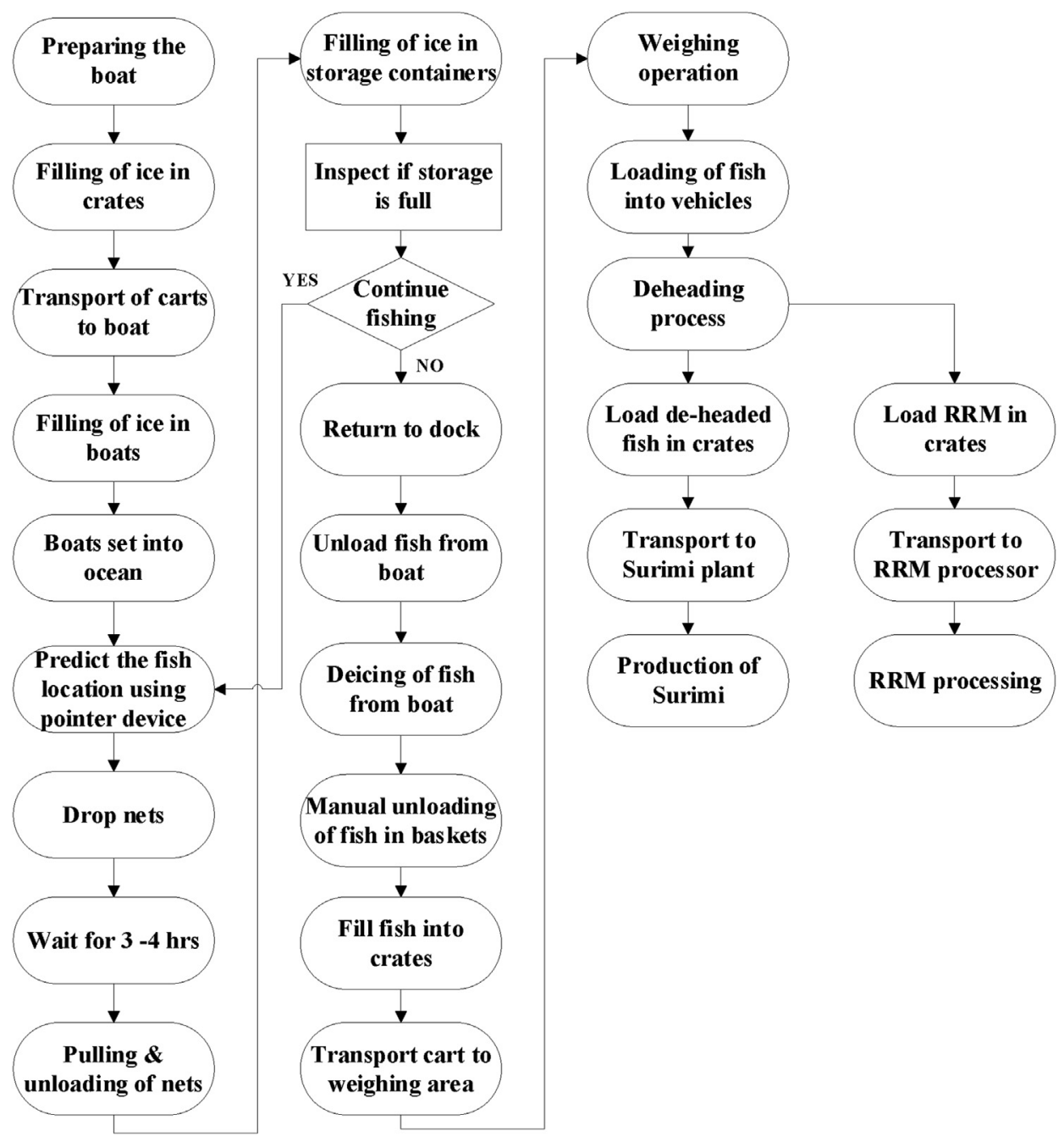

Fig. 3. Process flow diagram of operations in Surimi Processing.

Table 1

Parameters considered prior construction of value stream map.

\begin{tabular}{ll}
\hline Parameters & Ideals \\
\hline Demand & Uncertain demand \\
Type of fishing vessel & Mechanized fishing vessel \\
Fishing boat size & Overall length $15 \mathrm{~m}$ (110 HP engines) \\
Boat storage capacity & $25 \mathrm{MT}$ \\
Average fuel consumption (fishing) & $4000 \mathrm{~L}$ \\
Truck capacity & $10-15$ tons \\
Average fuel consumption (truck) & $4 \mathrm{~km} / \mathrm{L}$ \\
No of operators (fishing) & 15 \\
No of shifts per day(fishing) & 3 \\
Working hours per day (fishing) & $15 \mathrm{hrs}$ \\
Average working time per day (fishing) & $12 \mathrm{hrs} \mathrm{(excluding} \mathrm{intermittent} \mathrm{breaks)}$ \\
Total working time per day & $43200 \mathrm{~s}$ \\
\hline
\end{tabular}

\subsection{Simulation-based analysis}

Simulation models generated using Flexsim software are used as a visualizing tool to understand and communicate the real-time issues and depict improvements difficult to be practicalized. The software has inherent competence to estimate the energy in the machine, process, and plant-level (Paulista et al., 2019). The simulation models developed comprises the SSC divided into phases (i.e., fishing, dock, de-heading unit-surimi, de-heading unitRRM) to map the fragmented supply chain. All processes being interdependent contains inherent time variability. This variability is intricated in the model by the three-time estimates considered (i.e., optimistic, pessimistic and most likely time) for each operation used to simulate the model (Refer E-component). Different values generated owing system variability has been used to compute the related energy, the power consumed and emissions at different 


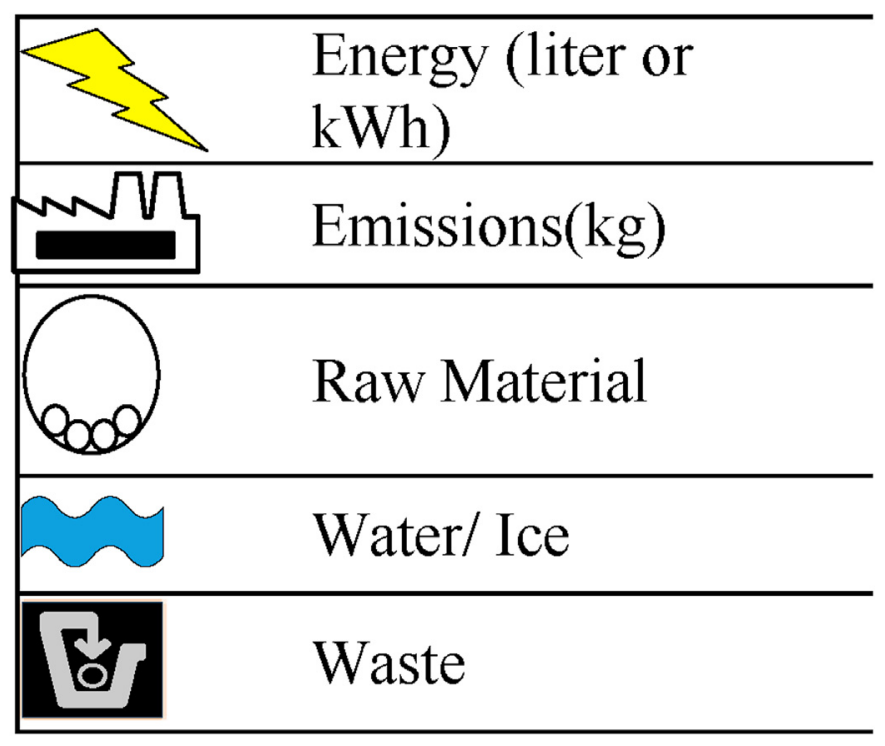

Fig. 4. Symbols used to represent environment waste.

times. Simulating each state with the necessary input data for thirty times gave the required performance measures whose averages are computed and tabulated due to the low standard deviations obtained (Golzarpoor and González, 2013). The quantity of water and ice used is kept constant irrespective of the catch size owing to the boat capacity. The initial raw material input was set at 15 tons of fish in the model simulated.

\subsection{Analyzing the current state value stream map}

An insight into the existing Indian SSC depicts the pressing need to mend the value stream w.r.t inferior quality, extended lead-time and energy consumption. The total lead time being 11.7 days (Fishing-RRM), the maximum VA occurs in the fishing phase contributing $462.33 \mathrm{~min}$. Contribution of NVA activities being on the extreme side mainly constitutes storage, transport and delay (Refer Fig. 5). Analyzing the NVA activities indicates a significant share from storage followed by wait and delay times, constituting $4.2 \%$ of the entire process lead time. Fishing posing an average duration of 9.3 days has an approximate fuel consumption of $3597 \mathrm{~L} /$ fishing trip. Before fish unload, an average waiting time of 180 min was witnessed. Added issues such as improper on-board cooling (despite the usage of large amounts of ice), manual touchpoints affecting quality, extensive exposure of fish, transportation delay and multiple inspection points reduce the productivity of this phase. The mode of operation containing multiple manual touchpoints affects fish quality. The absence of RRM processing centres in adjacent precincts necessitates extended transportation requiring adequate long-distance temperature maintenance followed by large fuel consumption. Hence it creates two scenarios i.e. the generated RRM is discarded (in most cases) or RRM is transported in iced condition for processing VAPs. The second case is expanded, considering the resource utilization by the case industry considered.

The current state of the SSC has an average total Energy Consumption (EC) of $3842 \mathrm{~L}$ of fuel and $1.28 \mathrm{kWh}$ of electricity per 15 tons of fish caught and pre-processed. Inputs such as 10 tons of ice and $0.5 \mathrm{~m}^{3}$ water are generally used during fishing and de-icing operations. Added use of ice is also found at pre-processing centres quantifying $100 \mathrm{~kg}$ and $200 \mathrm{~kg}$ for de-headed fish and RRM respectively. A wastage of $55 \mathrm{~kg}$ ice at pre-processing centres was also witnessed with no reuse of water and ice. Total emissions emitted constituted $14892 \mathrm{~kg}$, of which a mere $7.14 \%$ is utilized for VA. $\mathrm{CO}_{2}$ contribution being extreme constitutes $11469 \mathrm{~kg}$ followed by carbon sharing $3128.5 \mathrm{~kg}, \mathrm{NO}_{\mathrm{x}}$ providing $258.97 \mathrm{~kg}$ and the rest coming from $\mathrm{CH}_{4}, \mathrm{~N}_{2} \mathrm{O}, \mathrm{CO}$ and NMVOC in negligible amounts. A detailed depiction of the results obtained from the constructed static VSMs is represented in Table 2. Result scrutiny indicates that detached locations and condensed technology practice initiate quality deterioration and operational delays in the supply chain. It was also found that many on and off-board operations required process integration on the process level. Discussion with different stakeholders (i.e., fishers, aggregators and processors) regarding the current Indian SSC had also pointed out the vital need for improvements in productivity and quality at the downstream operations of the chain. Identification of the environmental wastes across the downstream operations of the SSC becomes essential in finding the synergy between the two symbiotic paradigms (i.e., lean and green). Conscription of the identified eanand green wastes, the possible root causes in the SSC have been represented in Fig. 6. Overproduction (lean waste) has been neglected in the Figure due to its negligible significance in the SSC.

\section{Future state environmental VSM}

Construction of future state maps requires answering the critical queries laid by Rother and Shook (2003) before mapping. The responses being the decision of the rate of production based on takt time, schedule of production based on bottleneck operation, the possibility of continuous flow, incorporation of a pull production system, and process improvement along the chain through development in cycle time. Being a process type industry, processing a single material to produce many products, determining the exact end demand remains an issue. Such concerns are countered by arbitrarily setting takt time and breaking orders based on the preset takt interval (Rother and Shook, 2003). The future state map is made to cater to a continuous flow, but practicing in a supply chain comprising perishable raw material is infeasible.

Gaining a deep understanding of the environmental wastes involved exposes many potentials in refining and regulating the SSC, maximizing effectiveness in all facets. Considering the inherent challenges in designing a non-existing model, the case organization had to deliberate improvements to cater to the primary function of the supply chain. The problem for the case organization despite marked improvements in lead time and sustainability, was the introduction of SCI. Renovating the supply chain structure and the associated costs involved a question of operation for the parent organization. Understanding such a classification was necessary considering the inherent competitive advantage of firms and organizational coordination achieved from SCI (Power, 2005). Furthermore the parent organization also felt the need for increased financial influence for improvements to occur among the fragmented stakeholders, possibly if the members come under one administrative canopy. This impact was revealed through DES. Improvements are incorporated enabling the decision-maker to explore unique possibilities without affecting the system studied (AbuKhousa et al., 2014). Static future state maps considering different levels of integrations are constructed and represented in Fig. 7 before generating the simulation model to garner adequate details obligatory to be incorporated into the future state models developed. The factors considered in the future state maps are Water consumed (WC), Power Consumed (PC), Raw Material Added (RMA), and Total Distance Travelled (TDT). Table 3 lists the consolidated results for 15 tons of fish obtained from both the static and simulated VSMs created.

Sixty Kaizens covering various aspects were proposed, out of 


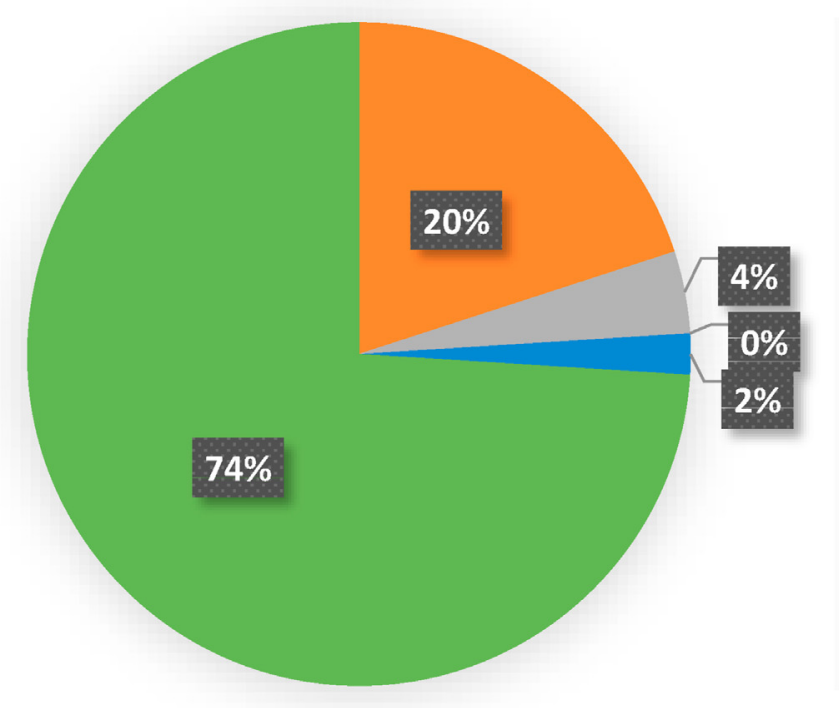

a) Share of Non Value Adding Activities

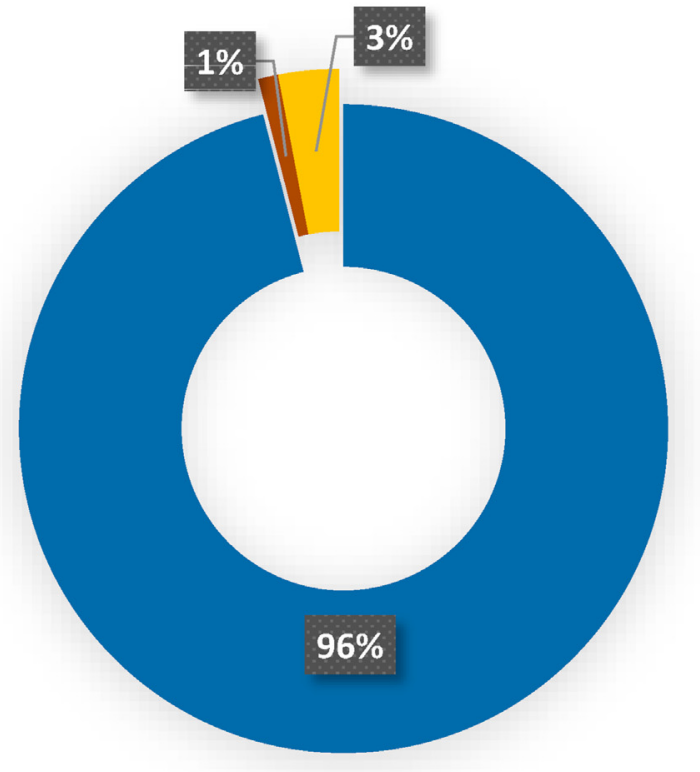

b) Storage $\%$ across the SSC stages
- Non Value Adding activities

Transport

Wait

Delay

Collection and

load

Storage

Fig. 5. Share of activities \& storage \% in the SSC.

Table 2

Current state map results.

\begin{tabular}{|c|c|c|c|c|c|c|}
\hline State/Phase & LT (days) & VAT (min) & NVAT (min) & PCE (\%) & EC (liters) & $\mathrm{EC}(\mathrm{kWh})$ \\
\hline Fishing Phase & 9.36 & 462.33 & 13022 & - & 3597 & - \\
\hline Dock Phase & 0.4 & 58 & 517 & - & 0.154 & 0.18 \\
\hline Surimi & 0.49 & 332 & 298.08 & - & 10.075 & 0.55 \\
\hline RRM & 1.45 & 332 & 1676.08 & - & 235.15 & 0.55 \\
\hline Total & 11.7 & 1184.33(Tp) & 15513.16 & 7.02 & 3842.37 & 1.28 \\
\hline
\end{tabular}

which 33 were chosen conditional to applicability. Decision making on Kaizen adoption was made from several discussions held with members of different cadres of the SSC (such as fishermen, skilled labors and manager working at aggregators and operators, managers and top management professionals of surimi and RRM processing plant) using a Likert scale ranging from 1 to 5 with one being disagreeable and five being the most desirable. The proposed Kaizens have been classified further based on Kaizens For 


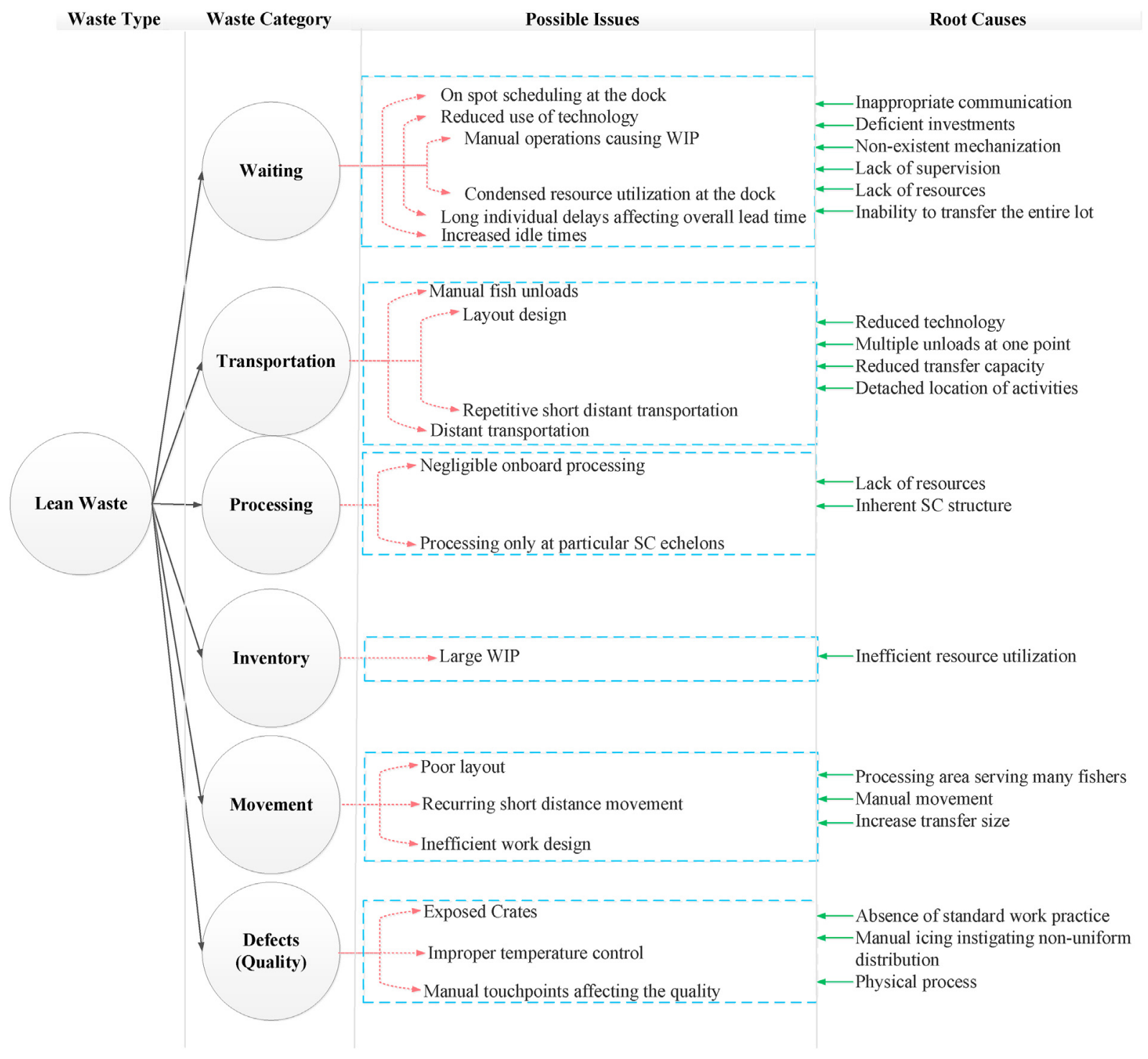

a) Lean wastes in the SSC

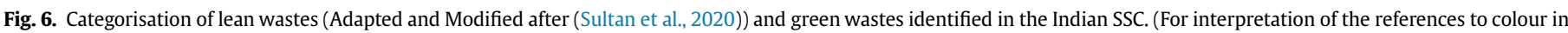
this figure legend, the reader is referred to the Web version of this article.)

Productivity Enhancement (KFPE), Kaizens For Quality (KFQ) and Kaizens For Productivity Enhancement and Quality (KFPE \& KFQ). Considering the ease and level of implementation, the Kaizens adopted are categorized into instantly applicable Kaizens like Kaizen Teian (Bottom-up improvement) and Kaizens that require supply chain moderations like Kaikaku (radical change) and Kakushin (breakthrough innovation) (Yuji and Monica, 2013).

\section{Results and discussions}

Results from simulations carried out on the future state maps provide optimistic results compared to static VSMs generated. Developments were unified by Kaizens and SCI, producing improvements enhancing both lead time and fish quality. Kaizen incorporation under different integration levels was observed and simulated. Proving highly decisive on expenses ready to be expended by the stakeholder, Kaizen performance was studied using a pilot study at specific suppliers with support from the surimi producer. The implemented Kaizens and the derived improvements from trial studies involving different levels of integration are listed in detail in the E-component. The concept of localization was verified based on the scope of implementation under NVI, PVI and CVI using DES.

Revamping any supply chain with lean principles depends on the acceptability of prime stakeholders with the obligation of proper lean training (Narayanamurthy et al., 2018). This thereby necessitates improvements based on stakeholder intention that are easy to adopt from the application of Kaizen Teian and process integrations. Primarily, NVI revealed a $10.08 \%$ reduction in lead time and $15.80 \%$ improvement in Value Added Time (VAT). Visible reductions of $67.5 \%$ were observed at the dock phase which primarily involved removing high unwanted waiting time. This supply 
chain inefficiency was rectified by applying lean thinking by the proper availability of material transfer and improved communications neglecting delays. Further delays were removed by process integrations that involved a combination of weighing and icing, removing cursory inspections and quick collection and preservation of RRM post-de-heading. Energy consumption and emissions produced showed a reduction of $1.51 \%$. However, PCE representing the amount of value-added into the process show simulated improvements of $6.58 \%$. The results obtained contented that the implementation of lean techniques could ensure operational and greener performances (Zhu et al., 2020).

The impression of PVI on the SSC happens with an increase in investments on Kaizen implementation, enabling the supply chain to implement the technology. This becomes possible owing to the financial foreclosure borne by the company stakeholders (Gilo et al., 2014), thereby easing monetary expenditure. Reduction in fishing time of $20.94 \%$ and overall lead time reductions of $25.04 \%$ was found to be achievable through the implementation of Kaizens.
Possible improvements were also visible from VAT in the dock phase $(29.569 \%)$ and NVAT in surimi processing $(80.401 \%)$. PVI showcased a high PCE of $7.68 \%$ in contrast to the current state. Reducing fishing time eventually decreases energy consumption. Savings of 5.96\% in energy is witnessed with an equivalent decrease in emissions. Total emissions were found to be $14331.13 \mathrm{~kg}$ with $\mathrm{CO}_{2}$ sharing $11037 \mathrm{~kg}$ in discharges while $\mathrm{C}-3011 \mathrm{~kg}$ constitutes the rest, $\mathrm{NO}_{\mathrm{x}}-249.06 \mathrm{~kg}, \mathrm{CH}_{4}, \mathrm{~N}_{2} \mathrm{O}, \mathrm{CO}$, and NMVOC forming the rest. Improvements like the usage of drones for fish spot identification, postpone de-heading operation to surimi processor characterize PVI. However, the results obtained support the statements of Han and Huo (2020), that aligning green thinking between supply chain stakeholders brings an absolute effect on the entire supply chain. Despite the environmental reductions and operational improvements witnessed in PVI, RRM underutilization due to the distant location of processors hinders in the complete exploitation of the value chain.

Erected on the mutual interest of supply chain partners for a

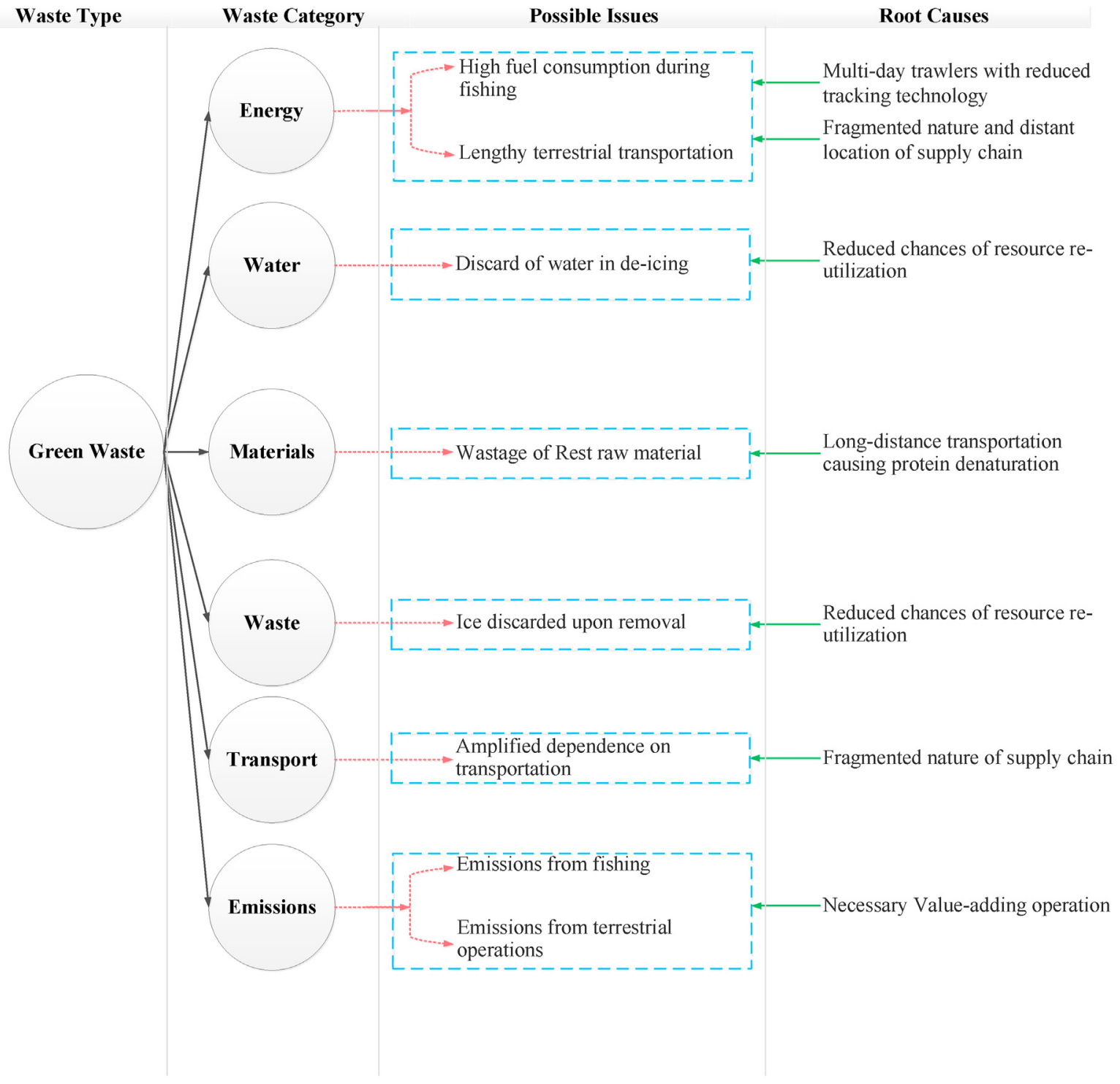

b) Green wastes in the SSC

Fig. 6. (continued). 


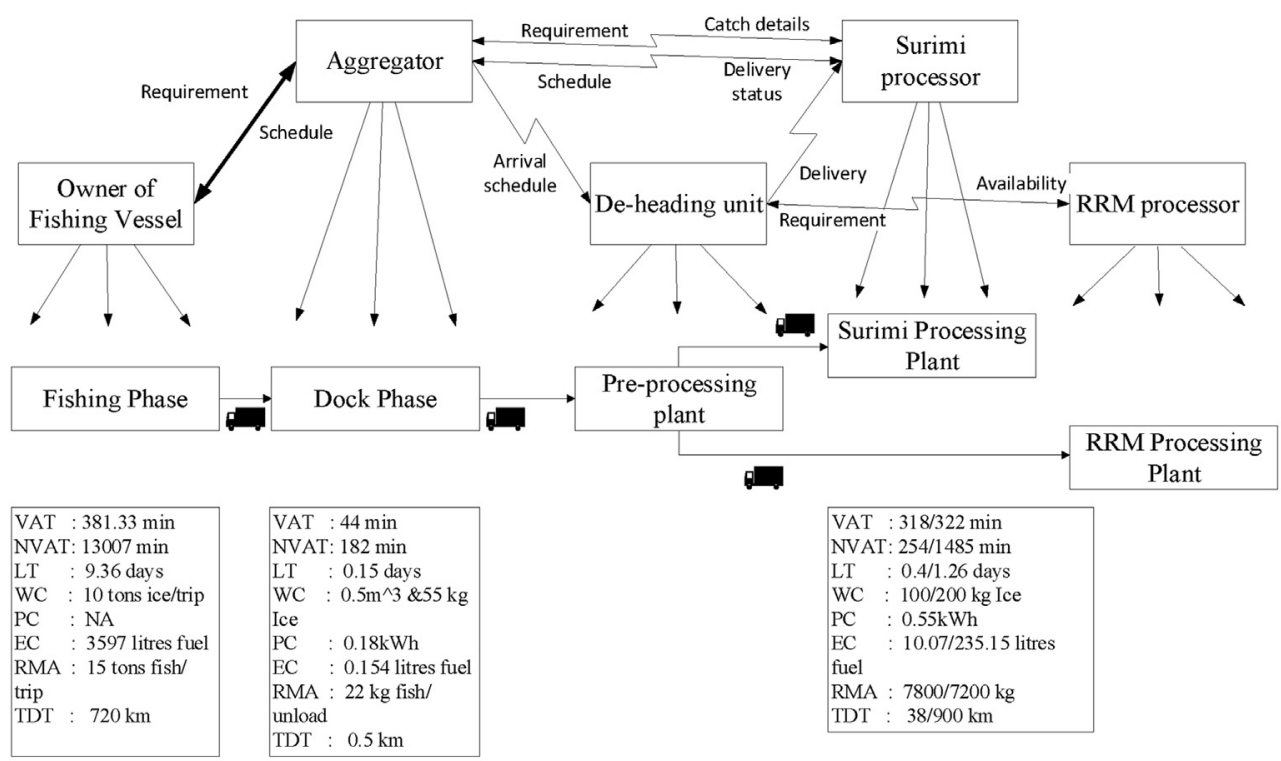

a) No Vertical Integration

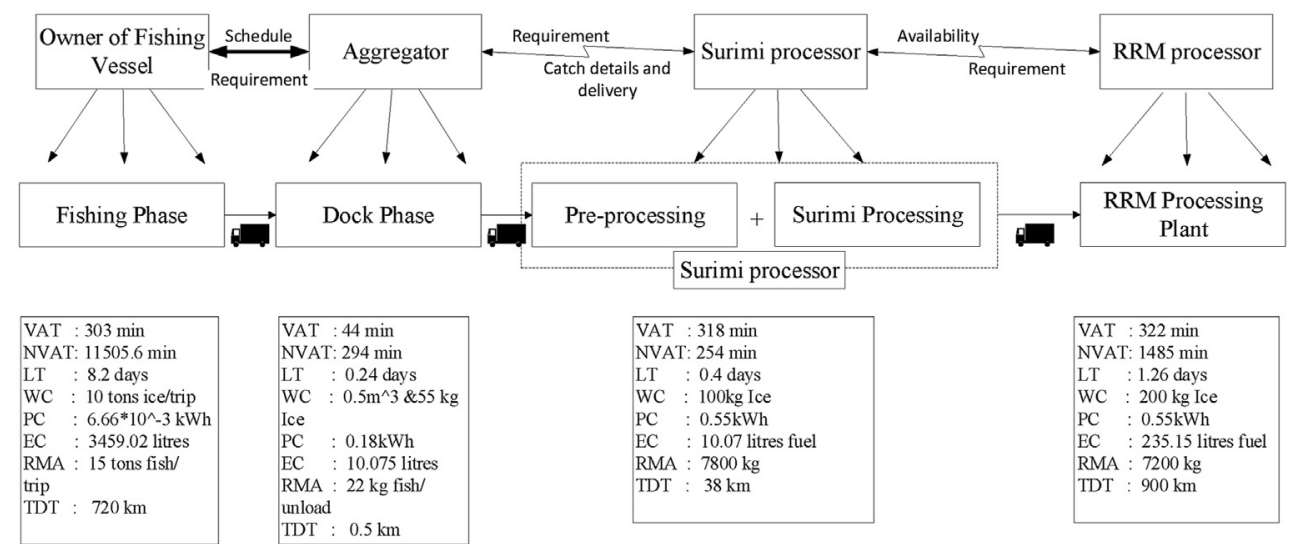

b) Partial Vertical Integration

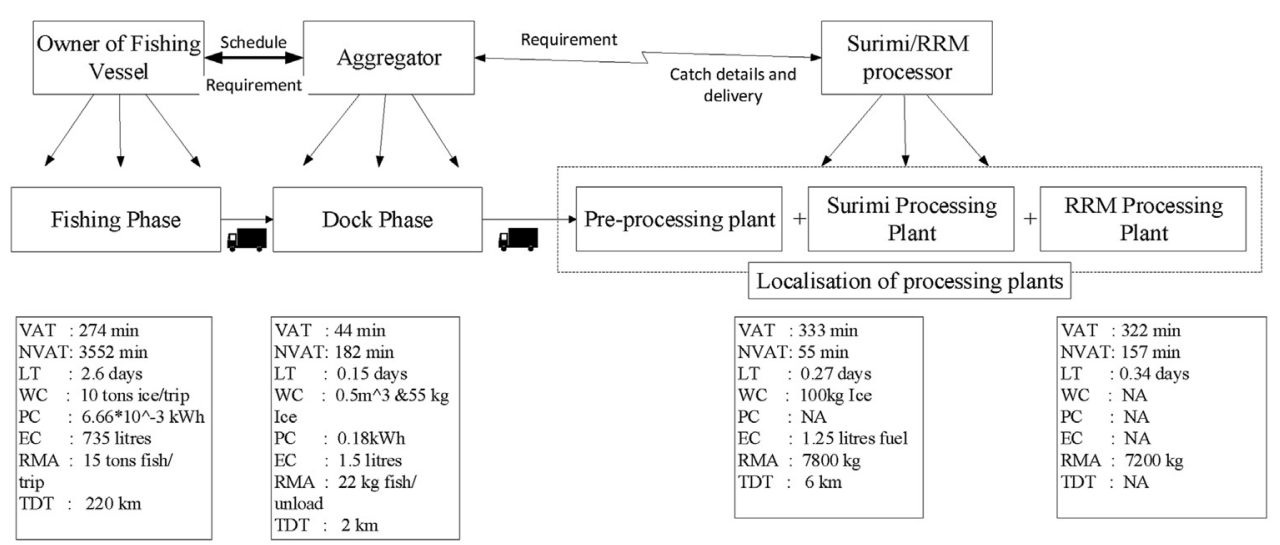

c) Complete Vertical Integration

Fig. 7. Proposed Future state Maps for different levels of Integration. 
Table 3

Performance indicators of the value stream maps.

\begin{tabular}{|c|c|c|c|c|c|c|c|}
\hline \multirow[t]{2}{*}{ Method } & State/Phase & LT (days) & VAT (min) & NVAT (min) & PCE (\%) & EC (liters) & $\mathrm{EC}(\mathrm{kWh})$ \\
\hline & \multicolumn{7}{|l|}{ Value Stream Map } \\
\hline \multirow[t]{6}{*}{ NoVertical Integration } & Fishing Phase & 9.3 & 381.33 & 13007 & - & 3597 & - \\
\hline & Dock Phase & 0.15 & 44 & 182 & - & 0.154 & 0.18 \\
\hline & Surimi & 0.4 & 318 & 254 & - & 10.075 & 0.55 \\
\hline & RRM & 1.26 & 322 & 1485 & - & 235.15 & 0.55 \\
\hline & Total & 10.97 & 1065.33(Tp) & 14928 & 6.74 & 3842.37 & 1.28 \\
\hline & Improvement (\%) & 6.23 & 10.04 & 3.7 & - & NA & NA \\
\hline \multirow[t]{6}{*}{ Partial Vertical Integration } & Fishing Phase & 8.2 & 303 & 11505.6 & - & 3459.02 & $6.66^{\mathrm{a}} 10^{-3}$ \\
\hline & Dock Phase & 0.24 & 44 & 294 & - & 10.075 & 0.18 \\
\hline & Surimi & 0.27 & 333 & 55 & - & 235.15 & - \\
\hline & RRM & 1 & 333 & 1485 & - & - & - \\
\hline & Total & 9.62 & 1013(Tp) & 13339.6 & 7.3 & 3704.245 & 0.3598 \\
\hline & Improvement (\%) & 17.77 & 14.46 & 14.01 & - & 3.59 & 71.89 \\
\hline \multirow[t]{7}{*}{ Complete Vertical Integration } & Fishing Phase & 2.6 & 274 & 3552 & - & 735 & $6.66^{\mathrm{a}} 10^{-3}$ \\
\hline & Dock Phase & 0.15 & 44 & 182 & - & 1.502 & 0.18 \\
\hline & Surimi & 0.27 & 333 & 55 & - & 1.25 & - \\
\hline & RRM & 0.34 & 333 & 157 & - & - & - \\
\hline & Total & 3.42 & 984(Tp) & 3946 & 19.98 & 938.502 & 0.3598 \\
\hline & Improvement (\%) & 70.76 & 16.91 & 74.56 & - & 75.57 & 71.89 \\
\hline & Simulation Results & & & & & & \\
\hline \multirow[t]{6}{*}{ Current state } & Fishing Phase & 9.36 & 462.33 & 13022 & - & 3597 & $6.66^{\mathrm{a}} 10^{-3}$ \\
\hline & Dock Phase & 0.4 & 58 & 517 & - & 0.154 & 0.18 \\
\hline & Surimi & 0.49 & 332 & 298.08 & - & 10.075 & 0.55 \\
\hline & RRM & 1.45 & 332 & 1676.08 & - & 235.15 & 0.55 \\
\hline & Total & 11.7 & $1184.33(\mathrm{Tp})$ & 15513.16 & 7.02 & 3842.37 & 1.28 \\
\hline & Improvement (\%) & NA & NA & NA & NA & NA & NA \\
\hline \multirow[t]{6}{*}{ NoVertical Integration } & Fishing Phase & 9.03 & 346.44 & 12771.21 & - & 3542.33 & - \\
\hline & Dock Phase & 0.13 & 40.85 & 146.35 & - & $1.51 \mathrm{E}-01$ & $1.77 \mathrm{E}-01$ \\
\hline & Surimi & 0.29 & 303.42 & 114.18 & - & 9.92 & 0.54 \\
\hline & RRM & 1.06 & 306.41 & 1119.99 & - & 231.57 & 0.54 \\
\hline & Total & 10.52 & 997.14(Tp) & 14151.73 & 6.58 & 3783.97 & 1.257 \\
\hline & Improvement (\%) & 10.08 & 15.80 & 8.77 & - & 1.51 & 1.79 \\
\hline \multirow[t]{6}{*}{ Partial Vertical Integration } & Fishing Phase & 7.4 & 281.33 & 10374.67 & - & 3391.22 & $6.52 \mathrm{E}-03$ \\
\hline & Dock Phase & 0.13 & 40.85 & 146.35 & - & 9.87 & 0.176 \\
\hline & Surimi & 0.26 & 315.98 & 58.42 & - & - & - \\
\hline & RRM & 0.93 & 327 & 1012.2 & - & 211.95 & - \\
\hline & Total & 8.77 & 965.16(Tp) & 11591.64 & 7.68 & 3613.04 & $1.83 \mathrm{E}-01$ \\
\hline & Improvement (\%) & 25.04 & 18.50 & 25.27 & - & 5.96 & 85.7 \\
\hline \multirow[t]{6}{*}{ Complete Vertical Integration } & Fishing Phase & 2.11 & 264.24 & 2774.16 & - & 702 & $6.31 \mathrm{E}-03$ \\
\hline & Dock Phase & 0.13 & 40.85 & 146.35 & - & 1.436 & 0.172 \\
\hline & Surimi & 0.47 & 315.98 & 360.82 & - & 1.195 & - \\
\hline & RRM & 0.27 & 327 & 61.8 & - & - & - \\
\hline & Total & 2.98 & 948.07(Tp) & 3343.13 & 22.09 & 704.631 & $1.78 \mathrm{E}-01$ \\
\hline & Improvement (\%) & 74.52 & 19.94 & 78.44 & - & 81.66 & 86.09 \\
\hline
\end{tabular}

${ }^{a}$ Values represented for 15 tons of fish.

long term stable benefit-sharing connection (Dong et al., 2020), CVI works on the principle of unifying the whole process of production from fishing until the production of RRM products. CVI is characterized by the amount of capital spent, ownership structure and management (Pinto and Diemer, 2020) with decision making relying on the top management. All upgrades and operations are controlled by the surimi processor (in our case), making execution easier. This level of integration introduces the concept of localization where RRM processing plants are localized nearby the surimi processing plant, thereby increasing RRM utilization by making raw material transfer more accessible. Localization scenarios were modelled considering distance values provided by the producer. The usage of single-day fishing trawlers (90 HP capacity) as collection boats and other enhancements (Refer E-component), can efficiently reduce the fishing lead time, having a considerable toll on environmental emissions with reduced fuel consumption. Despite the significant difference in catch quantity, the long raw material idle time gets reduced, giving superior quality surimi with the diminished use of resources. CVI provides reduced lead time of $74.52 \%$ and energy consumption of $704 \mathrm{~L}$ of fuel with $0.178 \mathrm{kWh}$ of electricity. Total emissions sum to $3025.90 \mathrm{~kg}$, of which $\mathrm{CO}_{2}$ contributes-2308.5 kg, C- $629.15 \mathrm{~kg}, \mathrm{NO}_{\mathrm{x}}-52.91 \mathrm{~kg}$ and the remaining is constituted by $\mathrm{CH}_{4}, \mathrm{~N}_{2} \mathrm{O}, \mathrm{CO}$ and NMVOC. Comparing the attained values with the current state, a massive reduction in emissions of $79.68 \%$ was evident with only $\mathrm{CO}_{2}$ constituting $79.87 \%$. VAT improved the maximum (42.86\%) in the fishing phase and NVAT decreased at its extreme (96.31\%) in utilizing RRM products. The analysis also showed that CVI produced the maximum cycle efficiency (214.67\%). The findings from this research work were found to be in coherence with the outcomes of Wiengarton and Langonni (2015) and Gimenez and Sierra (2013) who stated the positive influence of supply chain collaborations on the environment.

Regardless of results showing constructive outcomes, improvements in the Indian perspective according to Luthra et al. (2015) are generally subject to implementation barriers like high capital, absence of financing mechanism, lack of subsidies, lack of technology awareness, lack of training, lack of infrastructure, societal issues, geopolitical condition, government regulations which require a thorough scenario outlook. This therefore requires validation to understand the benefits perceived. Hence an attempt is made to understand the Profit vs. SCI interaction in the upcoming section as a ratification technique of the implementation barriers. 


\subsection{Economic analysis}

Fig. 8a) signifies the energy cost for the supply chain configurations based on the simulated lead time. This is done by cumulating the energies consumed (both fuel and electricity) for both the simulated and calculated values. Energy calculations use INR65.21 per liter diesel fuel and INR5 per kWh. Results show apparent outcomes of $80 \%$ energy savings (in cost) considering the simulated CVI lead time.

An additional classification is based on the supply chain operational cost (Refer Fig. 8b). Investigations reveal that a surimi block (10 kg weight) requires $24 \mathrm{~kg}$ of fish charged at an average of INR40 per $\mathrm{Kg}$. Handling costs at the dock are charged INR2 per kg, transportation to pre-processing centres charged at INR20 per kg. The Surimi processor holds a fixed operating cost of INR980 per kg (all-inclusive). The logistics altogether have a cumulative value of INR309 per $\mathrm{kg}$, including all transportations (INR2 per $\mathrm{kg}$ from the dock to the pre-processor \& INR11 per $\mathrm{kg}$ for transportation from the pre-processor to the surimi processing unit). As discussed earlier, PVI evades the pre-processor hence saving on both the preprocessing and related logistics cost. CVI is the most lucrative of all scenarios addressed earns the producer revenue of INR2019 per block compared to INR254 per block obtained presently. It is also necessary to be considered that the financial analysis does not include the supply chain transition cost as the proposed scenarios are yet to be adopted and quantifying renovation costs based on simulated outputs will be highly imaginative.

\section{Conclusion and future work}

This research concentrates on analyzing the downstream operations of surimi and associated RRM production and suggests improvements that can be applied across fish supply chains. The research article also extends its focus on overcoming issues of longer lead times and highlights the environmental potentials by identifying and concentrating on the concepts of supply chain
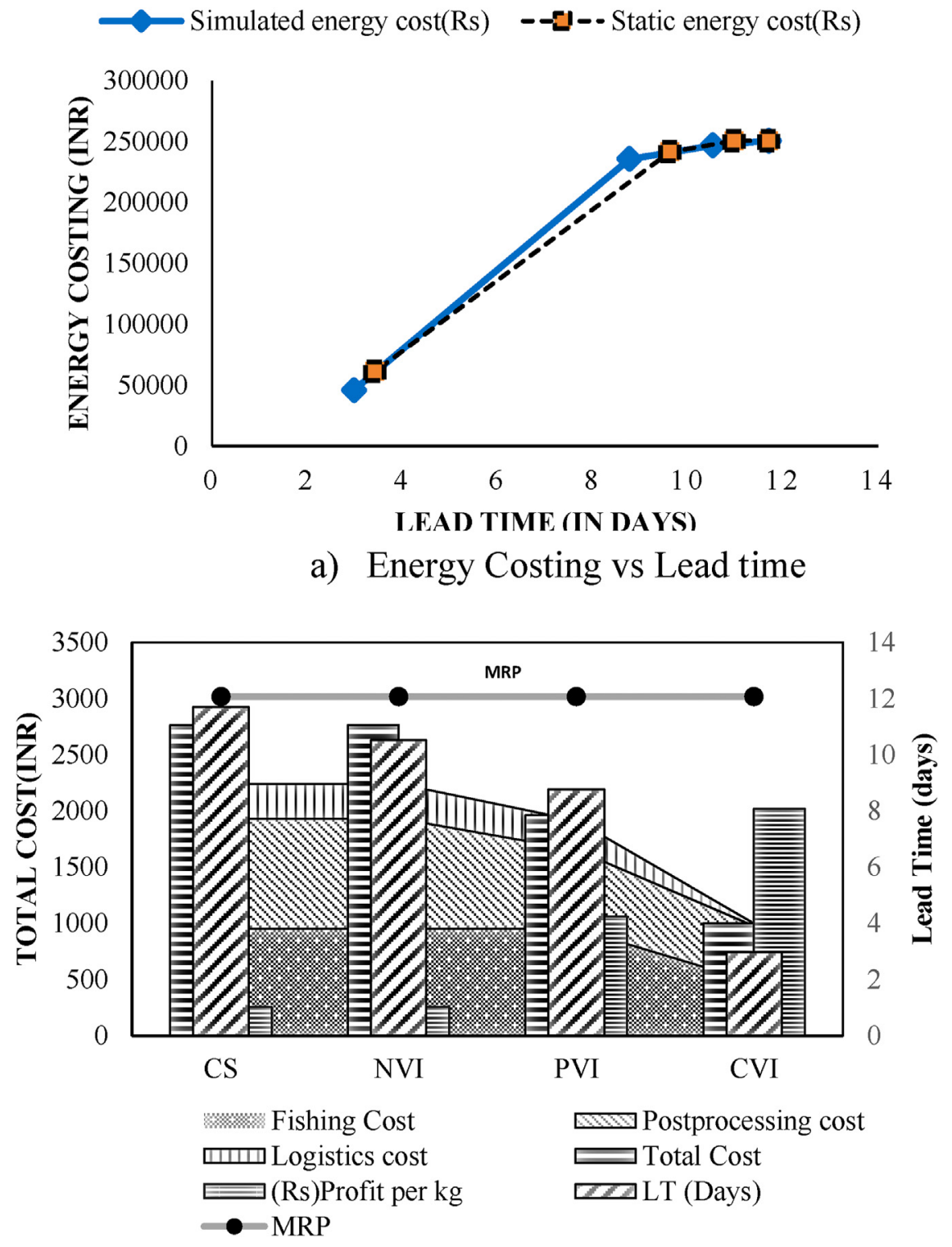

b) Total cost Vs Level of Integration

Fig. 8. Economic analysis. 
integration. Some significant conclusions derived from this research work are as follows:

- The existing value stream map for the Indian SSC requires operational modifications that directly have an influence on the environment.

- Operational modifications use lean and Kaizens, whereas environmental improvements achieve greater significance under supply chain integration with sustainable transportation modes

- Kaizens proposed covers improvements depending on execution capability

- A simulation model depicting variability and localization effects on the supply chain denoted a decrease in lead time by $74 \%$ and an $81 \%$ reduction in energy under CVI

- Energy costing showed an $80 \%$ reduction in energy expenses

- Operational costs reduced by $62.5 \%$ and profits increased by 87.41\% under CVI

- Emission reductions using simulated energy values obtained from DES were quantified and the best scenario (i.e., CVI) exhibited emission reductions of $79.8 \%$

- Results clarify the impulsive need for deep localization of processing plants for improved utilization and profits.

The outcomes of this research article also prove vital in recent times of Covid-19, where the reduction in manual touchpoints has been the new normal to reduce the spread of diseases. Results familiarize new technologies that limit raw material exposure prospering new market segments. Introducing a sustainable fish/ surimi supply chain in India according to the author, will likewise effectually assist in familiarising the Sustainable Development Goals (SDGs):- SDG 2(Zero hunger), SDG 12(Responsible consumption and production) by efficient use of RRM and SDG 13(Climate Action) by reducing emission levels preventing GHG emissions hence aiding in a production technique that is both cleaner and sustainable.

The current work on the Indian SSC provides an encouraging outlook into the future of surimi and VAPs from RRM. Further work needs to be carried out in terms of changeover cost, barriers, framework and step by step implementation of lean in the fishing scenario. The effect on local employability also requires considerable exploration to design a socioeconomically robust supply chain. The results obtained can be extended upstream, thereby enhancing the entire supply chain, including processes in the surimi industry.

\section{CRediT authorship contribution statement}

Farook Abdullah Sultan: Conceptualization, Methodology, Software, Data curation, Writing - original draft, Investigation, Visualization, Software, Validation, Writing. Srikanta Routroy: Conceptualization, Reviewing, Editing, Supervision. Maitri Thakur: Reviewing, Editing, Supervision.

\section{Declaration of competing interest}

The authors declare that they have no known competing financial interests or personal relationships that could have appeared to influence the work reported in this paper.

\section{Acknowledgments}

This work is supported by the ReValue project funded through the INNO-Indigo programme under a DBT India grant (BT/IN/INNOIndigo/12/NK/2017-18 dt. 21/02/18) and the Research Council of Norway project number 281262.

\section{Appendix A. Supplementary data}

Supplementary data to this article can be found online at https://doi.org/10.1016/j.jclepro.2020.125389.

\section{References}

Abideen, A., Mohamad, F.B., 2020. Improving the performance of a Malaysian pharmaceutical warehouse supply chain by integrating value stream mapping and discrete event simulation. J. Model. Manag. https://doi.org/10.1108/JM2-072019-0159. ISSN: 1746-5664.

AbuKhousa, E., Al-Jaroodi, J., Lazarova-Molnar, S., Mohamed, N., 2014. Simulation and modeling efforts to support decision making in healthcare supply chain management. Sci. World J. https://doi.org/10.1155/2014/354246. Article ID 354246, 2014

Anastasiadis, F., Apostolidou, I., Michailidis, A., 2020. Mapping sustainable tomato supply chain in Greece: a framework for research. Foods 9 (5), 539.

Barth, H., Melin, M., 2018. A Green Lean approach to global competition and climate change in the agricultural sector-A Swedish case study. J. Clean. Prod. 204, $183-192$.

Baumer-Cardoso, M.I., Campos, L.M., Santos, P.P.P., Frazzon, E.M., 2020. Simulationbased analysis of catalyzers and trade-offs in Lean \& Green manufacturing. J. Clean. Prod. 242, 118411.

Belayutham, S., González, V.A., Yiu, T.W., 2016. Clean-lean administrative processes: a case study on sediment pollution during construction. J. Clean. Prod. 126, 134-147.

Boopendranath, M.R., Pravin, P., 2006. Energy Conservation in Fishing Operations.

Brown, A., Amundson, J., Badurdeen, F., 2014. Sustainable value stream mapping (Sus-VSM) in different manufacturing system configurations: application case studies. J. Clean. Prod. 85, 164-179.

Carvalho, H., Govindan, K., Azevedo, S.G., Cruz-Machado, V., 2017. Modelling green and lean supply chains: an eco-efficiency perspective. Resour. Conserv. Recycl. $120,75-87$

Chaudhuri, A., Boer, H., Taran, Y., 2018. Supply chain integration, risk management and manufacturing flexibility. Int. J. Oper. Prod. Manag. https://doi.org/10.1108/ IJOPM-08-2015-0508.

Chen, H., Liu, S., Oderanti, F., 2020. A knowledge network and mobilisation framework for lean supply chain decisions in agri-food industry. In Supply Chain Logistics Manag.: Concepts, Methodol. Tools Appl. 369-381. IGI Global.

Cherrafi, A., Elfezazi, S., Chiarini, A., Mokhlis, A., Benhida, K., 2016. The integration of lean manufacturing, Six Sigma and sustainability: a literature review and future research directions for developing a specific model. J. Clean. Prod. 139, $828-846$.

Chiarini, A., 2014. Sustainable manufacturing-greening processes using specific Lean Production tools: an empirical observation from European motorcycle component manufacturers. J. Clean. Prod. 85, 226-233.

Cudney, E., Elrod, C., 2011. A comparative analysis of integrating lean concepts into supply chain management in manufacturing and service industries. Int. J. Lean Six Sigma. https://doi.org/10.1108/20401461111119422. ISSN: 2040-4166.

Dasgupta, M.S., Routroy, S., Widell, K.N., Bhattacharyya, S., Thakur, M., 2019. A Strategy for improved temperature control in the supply and processing stages of Surimi cold chain in India. IIR Int. Congress Refriger.DOI. https:// doi.org/10.18462/iir.icr.2019.131.

Dong, D.D., Moritaka, M., Liu, R., Fukuda, S., 2020. Restructuring toward a modernized agro-food value chain through vertical integration and contract farming: the swine-to-pork industry in Vietnam. J. Agribus. Dev. Emerg. Econ. https://doi.org/10.1108/JADEE-07-2019-0097. ISSN: 2044-0839.

Engelund, E.H., Breum, G., Friis, A., 2009. Optimisation of large-scale food production using Lean Manufacturing principles. J. Foodserv. 20 (1), 4-14. https:// doi.org/10.1111/j.1748-0159.2008.00109.x.

Faulkner, W., Badurdeen, F., 2014. Sustainable Value Stream Mapping (Sus-VSM): methodology to visualize and assess manufacturing sustainability performance. J. Clean. Prod. 85, 8-18.

Folinas, Dimitris, Aidonis, Dimitrios, Triantafillou, Dimitrios, Malindretos, Giorgos, 2013. Exploring the greening of the food supply chain with lean thinking techniques. Procedia Technol. 8 (1), 416-424.

Garza-Reyes, J.A., 2015. Lean and green-a systematic review of the state of the art literature. J. Clean. Prod. 102, 18-29.

Garza-Reyes, J.A., Al-Balushi, M., Antony, J., Kumar, V., 2016. A Lean Six Sigma framework for the reduction of ship loading commercial time in the iron ore pelletising industry. Prod. Plann. Contr. 27 (13), 1092-1111.

Garza-Reyes, J.A., Romero, J.T., Govindan, K., Cherrafi, A., Ramanathan, U., 2018. A PDCA-based approach to environmental value stream mapping (E-VSM). J. Clean. Prod. 180, 335-348.

Geary, S., Childerhouse, P., Towill, D.R., 2002. Uncertainty and the seamless supply chain. NO. 4 (JULY/AUG. 2002). Supply Chain Manag. Rev. 6, 52-61. ILL.

Gilo, D., Levy, N., Spiegel, Y., 2014. Partial vertical integration, ownership structure and foreclosure. Work. https://doi.org/10.1257/mic.20160058.

Gimenez, C., Sierra, V., 2013. Sustainable supply chains: governance mechanisms to greening suppliers. J. Bus. Ethics 116 (1), 189-203.

Golzarpoor, H., González, V., 2013. July. A green-lean simulation model for assessing environmental and production waste in construction. In Proc. 21 th Ann. Confer. Int. Group Lean Constr. 885-894. Fortaleza, Brazil. 
Gómez-Sanabria, A., Zusman, E., Höglund-Isaksson, L., Klimont, Z., Lee, S.Y., Akahoshi, K., Farzaneh, H., 2020. Sustainable wastewater management in Indonesia's fish processing industry: bringing governance into scenario analysis. J. Environ. Manag. 111241.

Gopakumar, G., 2002. Marine ornamental animals collection, culture and conservation. Fish. chimes 24 (9), 10-17.

Gurumurthy, A., Kodali, R., 2011. Design of lean manufacturing systems using value stream mapping with simulation. J. Manuf. Technol. Manag. https://doi.org/ 10.1108/17410381111126409. ISSN: 1741-038X.

Han, Z., Huo, B., 2020. The Impact of Green Supply Chain Integration on Sustainable Performance. Industrial Management \& Data Systems.

Henrique, D.B., Filho, M.G., Marodin, G., Jabbour, A.B.L.D.S., Chiappetta Jabbour, C.J., 2020. A framework to assess sustaining continuous improvement in lean healthcare. Int. J. Prod. Res. 1-20.

Jun, P., Gillenwater, M., Barbour, W., 2002. CO2, CH4, and N2 O emissions from transportation-water-borne-navigation [Background paper]. Good Practice Guidance Uncertain. Manag. National Greenhouse Gas Inventories 71-92.

King, A.A., Lenox, M.J., 2001. Lean and green? An empirical examination of the relationship between lean production and environmental performance. Prod. Oper. Manag. 10 (3), 244-256.

Kumar, A., Kushwaha, G., 2015. Value Stream Mapping: a Tool for Indian Agri-Food Supply Chain.

Kumar, S., Dhingra, A.K., Singh, B., 2018. Process improvement through Lean-Kaizen using value stream map: a case study in India. Int. J. Adv. Manuf. Technol. 96 (5-8), 2687-2698.

Kurdve, M., Hanarp, P., Chen, X., Qiu, X., Zhang, Y., Stahre, J., Laring, J., 2011. May. Use of environmental value stream mapping and environmental loss analysis in lean manufacturing work at Volvo. In Proc. 4th Swedish Prod. Sympos. (SPS11) $3-5$.

Larson, T., Greenwood, R., 2004. Perfect complements: synergies between lean production and eco-sustainability initiatives. Environ. Qual. Manag. 13 (4), $27-36$.

Luthra, S., Kumar, S., Garg, D., Haleem, A., 2015. Barriers to renewable/sustainable energy technologies adoption: Indian perspective. Renew. Sustain. Energy Rev. 41, 762-776.

Liu, C.L., Lee, M.Y., 2018. Integration, supply chain resilience, and service performance in third-party logistics providers. Int. J. Logist. Manag. https://doi.org/ 10.1108/IJLM-11-2016-0283. ISSN: 0957-4093.

Mannacharaju, M., Villalan, A.K., Shenbagam, B., Karmegam, P.M., Natarajan, P., Somasundaram, S., Arumugam, G., Ganesan, S., 2020. Towards sustainable system configuration for the treatment of fish processing wastewater using bioreactors. Environ. Sci. Pollut. Control Ser. 27 (1), 353-365.

Melcher, A., Acar, W., DuMont, P., Khouja, M., 1990. Standard-maintaining and continuous-improvement systems: experiences and comparisons. Interfaces 20 (3), 24-40.

Melin, M., Barth, H., 2020. Value stream mapping for sustainable change at a Swedish dairy farm. Int. J. Environ. Waste Manag. 25 (1), 130-140.

Mustosmäki, A., Oinas, T., Anttila, T., 2020. The Rise of Lean Organisations in Nordic Countries: How Recent Changes in Public Sector Management Are Shaping Working Life. Shaping and Re-shaping the Boundaries of Working Life.

Nambudri, S., 2018. India's seafood exports cross \$7 billion [Online] Available at: https://timesofindia.indiatimes.com/business/india-business/indias-seafoodexports-cross-7-billion/articleshow/64830505.cms. (Accessed 20 July 2019).

Narayanamurthy, G., Gurumurthy, A., Subramanian, N., Moser, R., 2018. Assessing the readiness to implement lean in healthcare institutions-A case study. Int. J. Prod. Econ. 197, 123-142.

National Fisheries Development Board, 2016. About Indian fisheries. Available at: http://nfdb.gov.in/about-indian-fisheries.htm. (Accessed 30 July 2019).

Park, J.W., 2005. Surimi and Surimi Seafood. CRC press.

Parker, R.W., Tyedmers, P.H., 2015. Fuel consumption of global fishing fleets: current understanding and knowledge gaps. Fish Fish. 16 (4), 684-696.

Paul, S., Bhattacharya, R.N., 2004. CO2 emission from energy use in India: a decomposition analysis. Energy Pol. 32 (5), 585-593.

Paulista, C.R., Peixoto, T.A., de Assis Rangel, J.J., 2019. Modeling and discrete event simulation in industrial systems considering consumption and electrical energy generation. J. Clean. Prod. 224, 864-880.

Pavnaskar, S.J., Gershenson, J.K., Jambekar, A.B., 2003. Classification scheme for lean manufacturing tools. Int. J. Prod. Res. 41 (13), 3075-3090.

Piercy, N., Rich, N., 2009. Lean transformation in the pure service environment: the case of the call service centre. Int. J. Oper. Prod. Manag. 29 (1), 54-76.

Pinto, J.T., Diemer, A., 2020. Supply chain integration strategies and circularity in the European steel industry. Resour. Conserv. Recycl. 153, 104517.

Pokuaa-Duah, G., Nadarajah, D., 2020. Value stream mapping in enhancing operational performance of Ghanaian food ProcessingIndustry: mediating role of supply chain collaboration. Int. J. Bus. Soc. Sci. 11 (4).

Power, D., 2005. Supply chain management integration and implementation: a literature review. Supply Chain Manag.: Int. J. https://doi.org/10.1108/ 13598540510612721. ISSN: 1359-8546.

Ravi, R., Vipin, P.M., Boopendranath, M.R., Joshy, C.G., Edwin, L., 2014. Structural changes in the mechanised fishing fleet of Kerala, South India. Indian J. Fish. 61 (2), 1-6.

Revilla, E., Saenz, M.J., 2017. The impact of risk management on the frequency of supply chain disruptions. Int. J. Oper. Prod. Manag. https://doi.org/10.1108/ IJOPM-03-2016-0129. ISSN: 0144-3577.

Rother, M., Shook, J., 2003. Learning to See: Value Stream Mapping to Add Value and Eliminate Muda. Lean Enterprise Institute.

Routroy, S., Dasgupta, M., Thakur, M., Bhattacharyya, S., Widell, K.N., 2019. Surimi value chain in India: a strategy for improved resource utilization. IIR Int Congress Refriger. https://doi.org/10.18462/iir.icr.2019.149.

Russell, R.S., Taylor-Iii, B.W., 2008. Operations Management along the Supply Chain. John Wiley \& Sons.

Salama, A., Greberg, J., Skawina, B., Gustafson, A., 2015. Analyzing energy consumption and gas emissions of loading equipment in underground mining. CIM J. 6 (4), 179-188.

Shah, R., Ward, P.T., 2003. Lean manufacturing: context, practice bundles, and performance. J. Oper. Manag. 21 (2), 129-149.

Song, Y., Cai, J., Feng, T., 2017. The influence of green supply chain integration on firm performance: a contingency and configuration perspective. Sustainability 9 (5), 763.

Stadnicka, D., Litwin, P., 2019. Value stream mapping and system dynamics integration for manufacturing line modelling and analysis. Int. J. Prod. Econ. 208, 400-411.

Stadnicka, D., Ratnayake, R.C., 2015. December. Simple approach for Value Stream Mapping for business process analysis. In 2015 IEEE Int. Confer. Indus. Eng. Eng. Manag. (IEEM) 88-94 (IEEE).

Sultan, F.A., Routroy, S., Thakur, M., 2020. Introducing traceability in the Indian Surimi supply chain. Mater. Today: Proceedings. https://doi.org/10.1016/ j.matpr.2019.12.333.

Thiede, S., Schönemann, M., Kurle, D., Herrmann, C., 2016. Multi-level simulation in manufacturing companies: the water-energy nexus case. J. Clean. Prod. 139, $1118-1127$.

Thorpe, A., Bennett, E., 2004. Market-driven international fish supply chains: the case of Nile perch from Africa's Lake Victoria. Int. Food Agribus. Manag. Rev. 7 (4), 40-57.

Tyedmers, P., 2004. Fisheries and energy use. Encycl Energy. 2, 683-693.

Tyedmers, P.H., Watson, R., Pauly, D., 2005. Fueling global fishing fleets. AMBIO A J. Hum. Environ. 34 (8), 635-638.

Wiengarten, F., Longoni, A., 2015. A nuanced view on supply chain integration: a coordinative and collaborative approach to operational and sustainability performance improvement. Supply Chain Manag.: Int. J. https://doi.org/10.1108/ SCM-04-2014-0120. ISSN: 1359-8546.

Wills, B., 2009. The business case for environmental sustainability (Green): achieving rapid returns from the practical integration of lean \& green. Bus. Case Environ. Sustain. 13 (1), 32-38.

Wong, C.Y., Wong, C.W., Boon-Itt, S., 2015. Integrating environmental management into supply chains: a systematic literature review and theoretical framework. Int. J. Phys. Distrib. Logist. Manag. 45 (1/2), 43-68.

Wu, G.C., 2013. The influence of green supply chain integration and environmental uncertainty on green innovation in Taiwan's IT industry. Supply Chain Manag.: Int. J. https://doi.org/10.1108/SCM-06-2012-0201. ISSN: 1359-8546.

Yuji, Y., Monica, B., 2013. Manufacturing process innovation initiatives at Japanese manufacturing companies. J. Manuf. Technol. Manag. ISSN 1741-038X.

Zahoor, S., Abdul-Kader, W., Ijaz, H., Khan, A.Q., Saeed, Z., Muzaffar, S., 2019. A combined VSM and kaizen approach for sustainable continuous process improvement. Int. J. Indus. Eng. 1 (2), 125-137.

Zhu, X.Y., Zhang, H., Jiang, Z.G., 2020. Application of green-modified value stream mapping to integrate and implement lean and green practices: a case study. Int. J. Comput. Integrated Manuf. 33 (7), 716-731. 